Proc. Indian Acad. Sci. (Earth Planet. Sci.), Vol. 105, No. 1, March 1996, pp. 1-16.

(c) Printed in India.

\title{
Atmospheric surface layer parameters during different phases of monsoon over Varanasi from MONTBLEX-90
}

\author{
D V VISWANADHAM and A N V SATYANARAYANA \\ Department of Geophysics. Banaras Hindu University, Varanasi 221005 , India
}

\begin{abstract}
The fast and slow response data $(8 \mathrm{~Hz}$ and $1 \mathrm{~Hz}$ respectively), obtained from the MONTBLEX-90 programme, are analysed for computing various surface layer parameters and the fluxes of sensible heat and momentum. In the present paper these fluxes, the Monin-Obukhov length scale $(L)$, the turbulent kinetic energy (TKE) and the intensity of turbulence $\left(\sigma_{w}\right)$ over Varanasi have been computed during different phases of monsoon such as dry, weak, moderate and active. Typical days are chosen for studying the above-mentioned parameters.
\end{abstract}

Keywords. Surface layer: TKE; sensible heat flux.

\section{Introduction}

The first few tens of meters of the atmosphere, commonly referred to as the surface layer, where most of the interaction takes place between the earth's surface and the overlying atmosphere, has attracted a lot of attention during the last several decades not only because it can be probed thoroughly, but in view of its importance in various exchange processes and its distinct characteristics. This surface layer acts as the main link between the boundary forcings at the surface and the atmosphere above it consisting of the mixed layer and free atmosphere. The energy for the main driving force of the atmosphere is derived mainly from the surface, particularly heat in different forms.

One of the most important features of the monsoon is the presence of a semi-permanent system known as the monsoon trough in the Indo-Gangetic belt normally extending from the Head of the Bay of Bengal to Pakistan, which accounts for rainfall in this part of the country. If the trough is active, low pressure systems such as depressions are generated in the Head of the Bay and move along the trough bringing copious rainfall. It is of interest to study the fluxes and the characteristics of the surface layer during different phases of the monsoon. Some of the earlier studies on the atmospheric surface layer are Businger et al (1971), Pruit et al (1973), Champagne et al (1977), Holt and Sethuraman (1985) etc., on various aspects of computing the surface layer fluxes and other parameters. In the present paper the fluxes of sensible heat and momentum, the Monin-Obukhov length scale and the intensity of turbulence over Varanasi using fast and slow response data obtained from MONTBLEX-90 during various phases of the monsoon have been studied.

\section{Site description}

The tower, which is a triangular open lattice structure for free passage of air, is installed in a large agricultural farm at the BHU campus. The farm consists of several fields of 
crops of different varieties. Adjacent to the field is a runway extending from the eastern side of the tower. The prevailing wind direction during the monsoon is mostly from SE and $\mathrm{S}$, and sometimes from NW. There is almost an uninterrupted fetch of more than a kilometre in the prevailing sectors, i.e., from West to East through the South. In the $\mathrm{NE}$ sector there are, however, trees at a distance of more than $300 \mathrm{~m}$. The receiving unit is located at a distance of $75 \mathrm{~m}$ from the western side of the tower. The height of the hut in which the receiving unit was kept is only around $2 \mathrm{~m}$ and hence cannot be an obstruction to the observations. The varieties of crops grown had heights of up to $1 \mathrm{~m}$. The site as a whole can be considered one of the best available in Varanasi.

\section{Data}

The fast response data $(8 \mathrm{~Hz})$ were acquired using a sonic anemometer (at $4 \mathrm{~m}$ ) and a Gill Propellor (at $15 \mathrm{~m}$ ). The fast response data were collected three-hourly, i.e., at $0530,0830,1130,1430,1730$ and $2330 \mathrm{hrs}$, for 10 minutes duration. The slow response data $(1 \mathrm{~Hz})$ at $1 \mathrm{~m}, 4 \mathrm{~m}$, and $30 \mathrm{~m}$ consist of wind speed, temperature and relative humidity. For the present study, five days i.e., $6 \mathrm{th}, 27$ th and 28 th July and 18 th and 19 th August 1990 were chosen.

\section{Quality check}

Before using the raw fast response data for the final analysis, caution should be exercised since they contain noise in the form of unusually high and low values. So the data are conditioned so as to be usable for statistical purposes since the present study concerns the statistical properties of turbulent quantities. The conditioning has been done as follows.

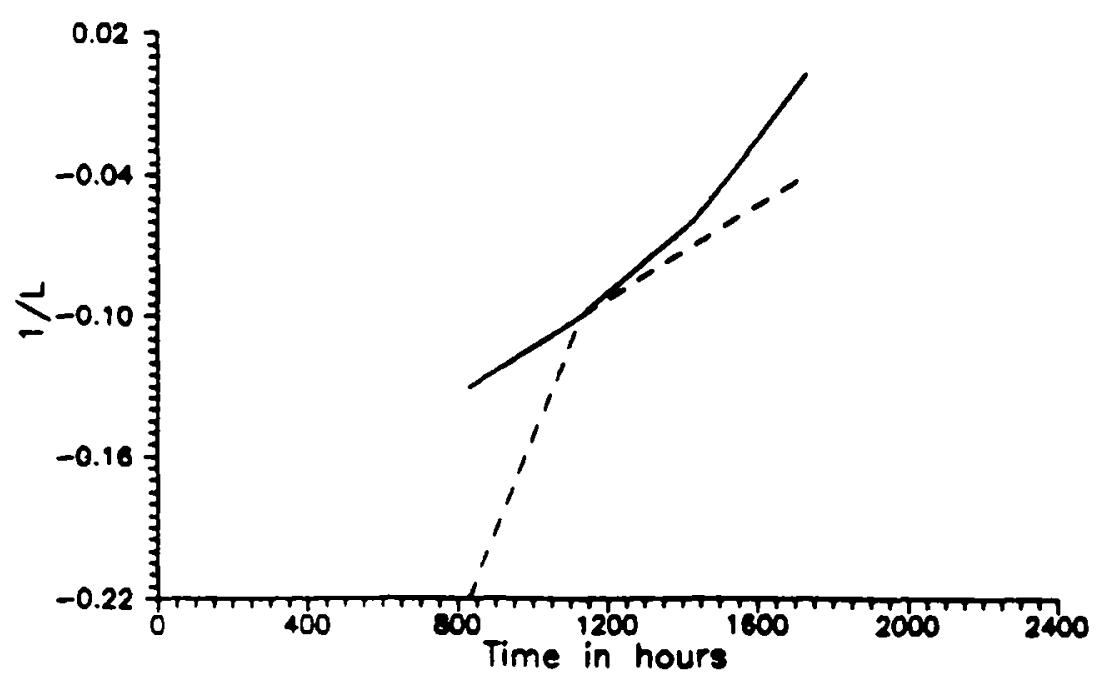

Figure 1. Diumal variation of $1 / L$ on 6 th July, $1990 ; 1-4 \mathrm{~m}$ layer (solid line), 4-30 $\mathrm{m}$ layer (dashed line). 
First a physical check of the whole data set, i.e., for 10 minutes duration, has been made. Any unusual or spurious spikes are removed and replaced by a limited value, taken at par with the highest among other fluctuations. Then its standard deviation is determined. Any individual value falling within \pm 3 standard deviations from the mean is retained and the rest are replaced by mean \pm 3 standard deviations. Wherever trends are noticed in the data set, they are removed by detrending the data with the least squares technique (Stull 1988) so as to ensure the quasi-random behaviour of turbulence.

The spectral densities of some turbulent parameters have been computed with the auto-correlation technique for the complete data set by the method of Blackman and Tukey (1958). A plot is made for the frequency vs. spectral density on a log-log paper. The best fit lines are obtained to see the general agreement. The analysis is carried out for all the fast data components. (Viswanadham and Satyanarayana 1992). This is one of the quality checks made to ensure the validity of the experimental data. Those cases where the power is between -1.3 and -1.8 only have been retained. There were very few data sets which differed significantly from universality and such data sets are ignored.

\section{Methodology}

\subsection{Flux computation using fast response data}

The fluxes from the high frequency data can be determined by the eddy correlation technique.

The fluxes have been computed from the following formulae.

Where

$$
\begin{aligned}
\text { momentum flux }(\mathrm{MF}) & =\rho U_{*}^{2} \mathrm{Nm}^{-2} \\
\text { sensible heat flux }(\mathrm{SHF}) & =-\rho C_{p d}(1+0.81 q) U_{*} \theta_{*} \mathrm{Wm}^{-2} .
\end{aligned}
$$

$$
\begin{aligned}
& U_{*}=\left(\overline{u^{\prime} w^{\prime 2}}+\overline{v^{\prime} w^{\prime 2}}\right)^{1 / 4}, \\
& \theta_{*}=-\overline{w^{\prime} \theta^{\prime}} / U_{*} .
\end{aligned}
$$

The Monin-Obukhov length scale $(L)$ can be obtained as follows.

$$
L=T U_{*}^{2} / g k \theta_{*}(\mathrm{~m}) \text {. }
$$

The turbulent intensity is

$$
\sigma_{w}=\left(w^{\prime 2} / \mathrm{N}\right)^{1 / 2} \mathrm{~ms}^{-1}
$$

where $\mathrm{N}$ is the number of sample points.

The sonic anemometre data have been sparse due to the non-working of the sensor much of the time. Therefore, only one day i.e., 27 th July, is taken to compute surface layer parameters.

\subsection{Flux computation using slow response data}

Using the slow response data the $U_{*}$ and $\theta_{*}$ can be computed in the following way. The dimensionless wind shear $\left(\varphi_{m}\right)$ and temperature shear $\left(\varphi_{h}\right)$ are given by $\left(k z / U_{*}\right)(\partial U / \partial z)$ and $\left(k z / \theta_{*}\right)(\partial T / \partial z)$ respectively. These shears are strongly related to the stability. The final relations for the parameters are the following. 
For unstable cases:

$$
\begin{aligned}
& U_{*}=\left(U_{2}-U_{1}\right) /\left(1 / k \ln \left(z_{2} / z_{1}\right)-\psi_{1}\right) . \\
& \theta_{*}=\left(T_{2}-T_{1}\right) /\left(0.74 \ln \left(z_{2} / z_{1}\right)-\psi_{2}\right) .
\end{aligned}
$$

For stable cases:

Here

$$
\begin{gathered}
U_{*}=\left(U_{2}-U_{1}\right) /\left(1 / k \ln \left(z_{2} / z_{1}\right)+4 \cdot 7 z / L\right) . \\
\theta_{*}=\left(T_{2}-T_{1}\right) /\left(0 \cdot 74 \ln \left(z_{2} / z_{1}\right)+4 \cdot 7 z / L\right) .
\end{gathered}
$$

$$
\begin{aligned}
\psi_{1}= & 2 \ln ((1+x) / 2)+\ln \left((1+x)^{2} / 2\right)-2 \tan ^{-1} x+\pi / 2 \\
& x=(1-15 z / L)^{1 / 4}=1 / \varphi_{m} . \\
\psi_{2}= & \ln \left(1+(1-9 z / L)^{1 / 2} / 2\right) .
\end{aligned}
$$

The three parameters $U_{*}, \theta_{*}$ and $L$ are not independent and each is a function of at least one other parameter, so their determination requires an iteration technique. The initial guess needed to compute the parameters $U_{*}$ and $\theta_{*}$ is obtained from the neutral profile. These are substituted in the expression to compute $L$. The new $L$ is substituted to compute both $U_{*}$ and $\theta_{*}$ which in turn are made use of to compute new $L$. This process of iteration is continued till convergence for $L$ is attained. The convergence limit is kept at the fifth decimal. Making use of the gradient observations, the above parameters have been computed for each of the data sets.

Using these parameters the fluxes from the slow response data are computed by (1) and (2). These fluxes are computed for the layers $1-4 \mathrm{~m}$ and $4-30 \mathrm{~m}$.

\section{Delineation of monsoon phases}

The conventional delineation into active and break phases gives rise to some inconsistencies over Varanasi. For example during IOP (Intensive Observational Period) the monsoon was rather weak in some cases. Hence based on the actual observation of rainfall and cloud amount a simple criterion is evolved to delineate the activity of monsoon into four cases viz., dry (D), weak (W), moderate (M) and active (A). Table 1

Table 1. Categorization of various monsoon phases.

\begin{tabular}{cccccc}
\hline & \multicolumn{5}{c}{ Cloud amount (octas) } \\
Rainfall(mm) & 0 & $\leqslant 2$ & $2-4$ & $4-6$ & $6-8$ \\
\hline 0 & D & D & W & M & A \\
$0-10$ & - & W & W & M & A \\
$>10-20$ & - & W & M & M & A \\
$>20-30$ & - & M & M & A & A \\
$>30-40$ & - & M & A & A & A \\
$>40$ & - & A & A & A & A \\
\hline
\end{tabular}

D - Dry; W - Weak; M - Moderate; A - Active. 
Table 2. Surface layer parameters from sonic data on 27 th July.

\begin{tabular}{lcrrrrr}
\hline Time & $\begin{array}{c}\text { MF } \\
\left(\mathbf{N m}^{-2}\right)\end{array}$ & $\begin{array}{c}\text { SHF } \\
\mathbf{W m}^{-2}\end{array}$ & $\begin{array}{c}U_{*} \\
\mathrm{~ms}^{-1}\end{array}$ & $\begin{array}{c}\theta_{*} \\
\mathbf{K}\end{array}$ & \multicolumn{1}{c}{$\begin{array}{c}L \\
\mathbf{m}\end{array}$} & $\begin{array}{c}\sigma_{w} \\
\mathrm{~ms}^{-1}\end{array}$ \\
\hline 1030 & 0.0566 & 33.00 & 0.2126 & -0.1294 & -26.76 & 0.3138 \\
1330 & 0.0032 & 19.44 & 0.6852 & -0.0236 & -1515.53 & 0.1875 \\
1430 & 0.0015 & 82.44 & 0.3000 & -0.2290 & -30.00 & 0.2760 \\
2030 & 0.0118 & 2.28 & 0.0979 & -0.0194 & -37.50 & 0.1119 \\
2130 & 0.0121 & -1.68 & 0.1023 & 0.1023 & 58.14 & 0.1287 \\
\hline
\end{tabular}

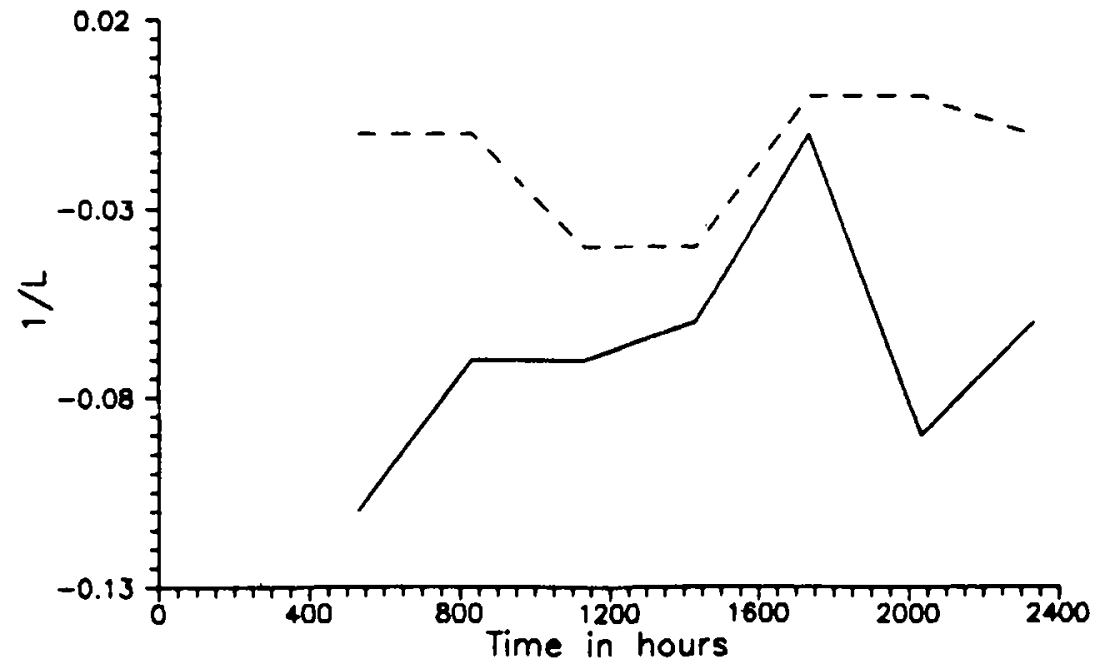

Figure 2. Diurnal variation of $1 / L$ on $28 \mathrm{th}$ July, 1990; 1-4 m layer (solid line), 4-30 $\mathrm{m}$ layer (dashed line).

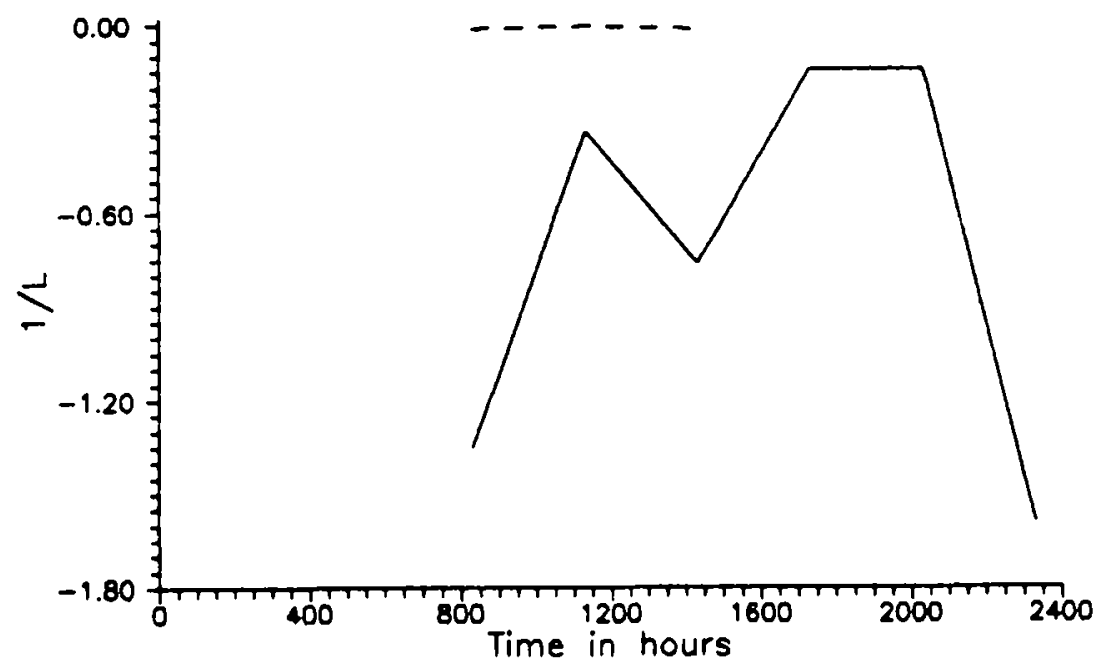

Figure 3. Diurnal variation of $1 / L$ on 19 th August, 1990; 1-4 m layer (solid line), 4-30 $\mathrm{m}$ layer (dashed line). 
shows the details. These are evolved for studying only the micrometeorology over Varanasi. Accordingly 6th July represents the moderate and 27th and 28th July the active phases; 18th and 19th August represent the dry case.

\section{Results and discussion}

Table 2 shows the surface layer parameters obtained at $4 \mathrm{~m}$ level from the sonic anemometer during the active phase. The diurnal variation is visible although the magnitudes do not differ significantly.

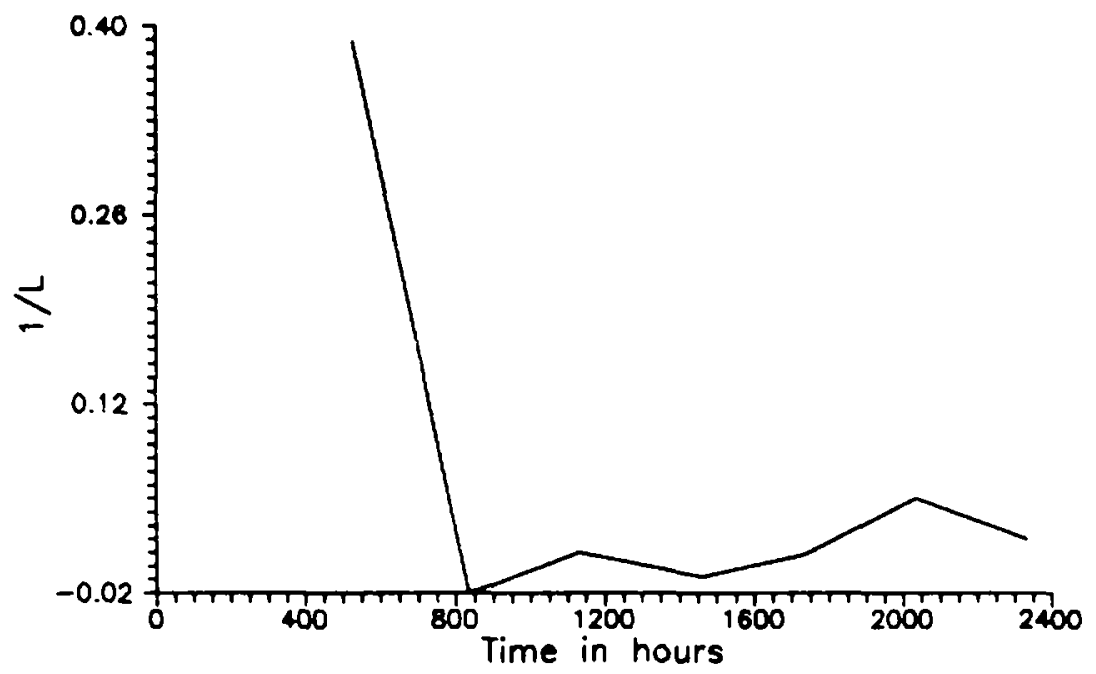

Figure 4. Diurnal variation of $1 / L$ on 6 th July, 1990 at $15 \mathrm{~m}$ height.

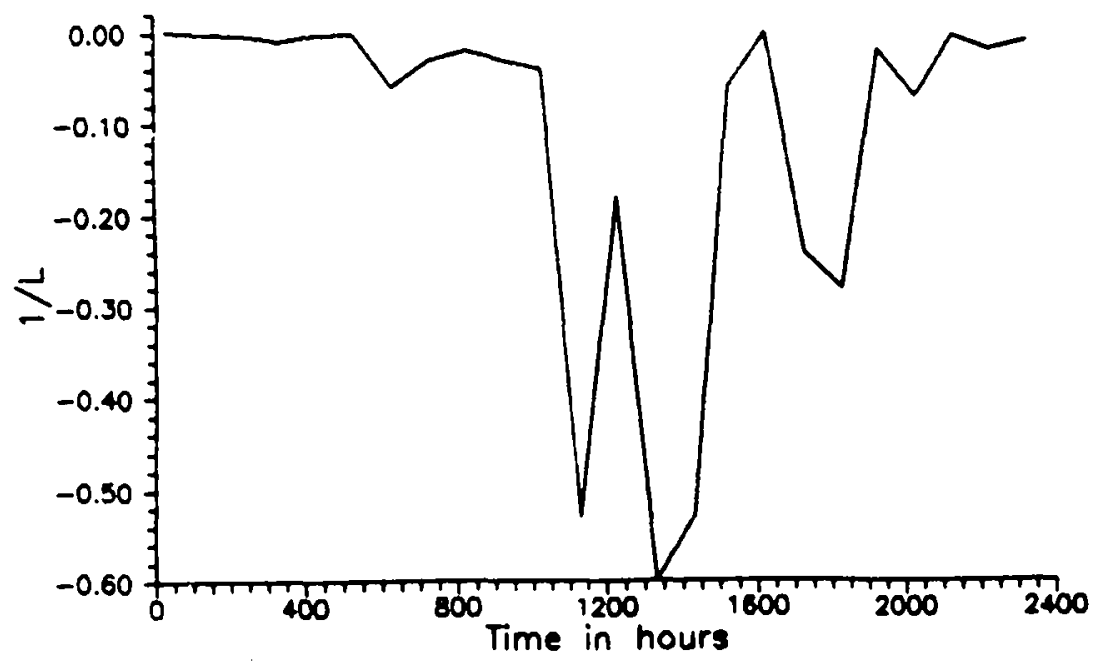

Figure 5. Diurnal variation of $1 / L$ on $28 \mathrm{th}$ July, 1990 at $15 \mathrm{~m}$ height. 
The different parameters are discussed hereunder for both the layers and at $15 \mathrm{~m}$ level.

\subsection{Monin-Obukhov length scale}

Figures 1 to 3 indicate the diurnal variation of $1 / L$ on 6 th July, 28th July and 19 th August respectively, for the layers $1-4 \mathrm{~m}$ and 4-30 m. Figures 4 to 6 depict $1 / L$ at $15 \mathrm{~m}$ height for the same dates respectively.

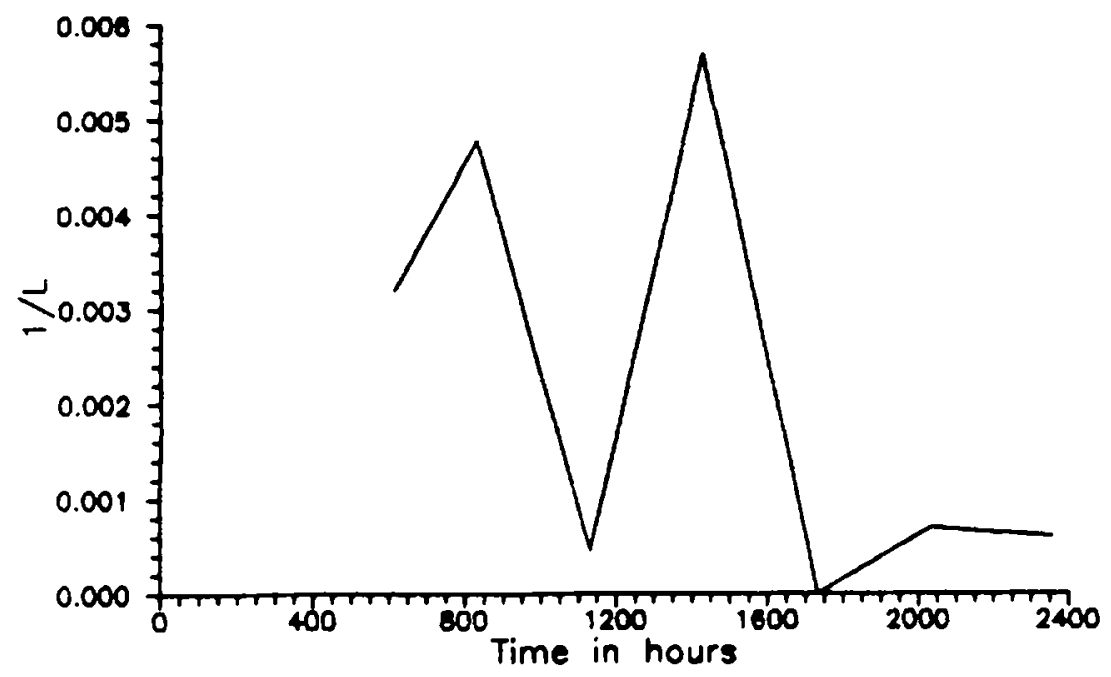

Figure 6. Diurnal variation of $1 / L$ on $19 \mathrm{th}$ August, 1990 at $15 \mathrm{~m}$ height.

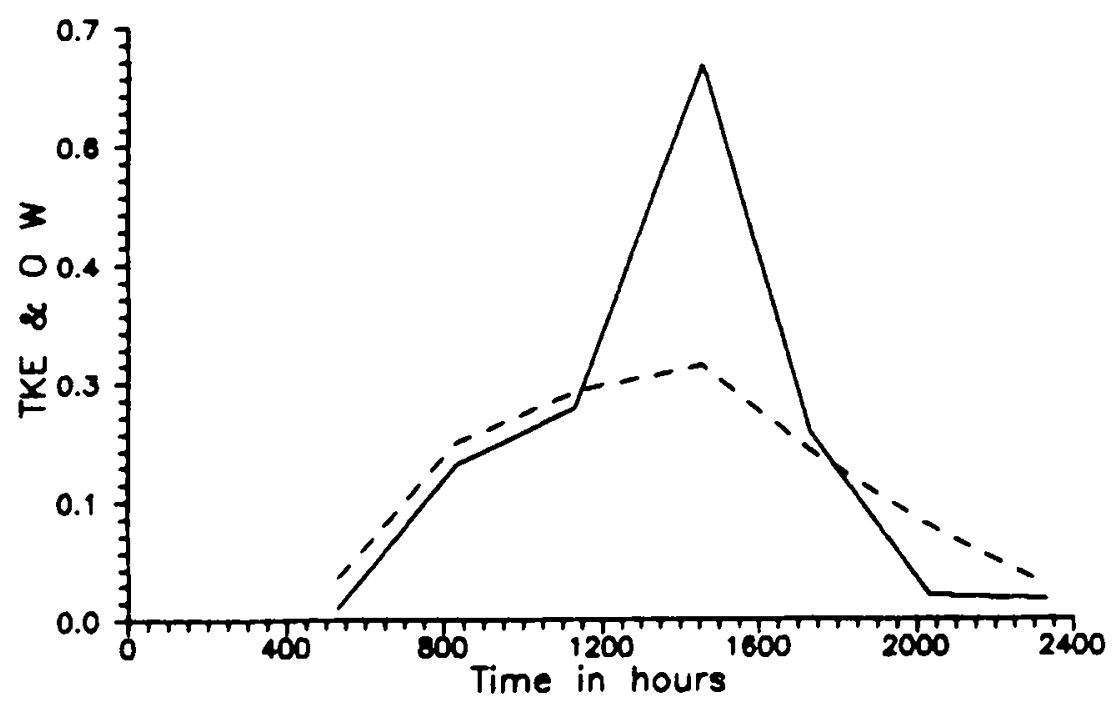

Figure 7. Diurnal variation of TKE (solid line) and O W (dashed line) on 6th July, 1990 at $15 \mathrm{~m}$ height. 

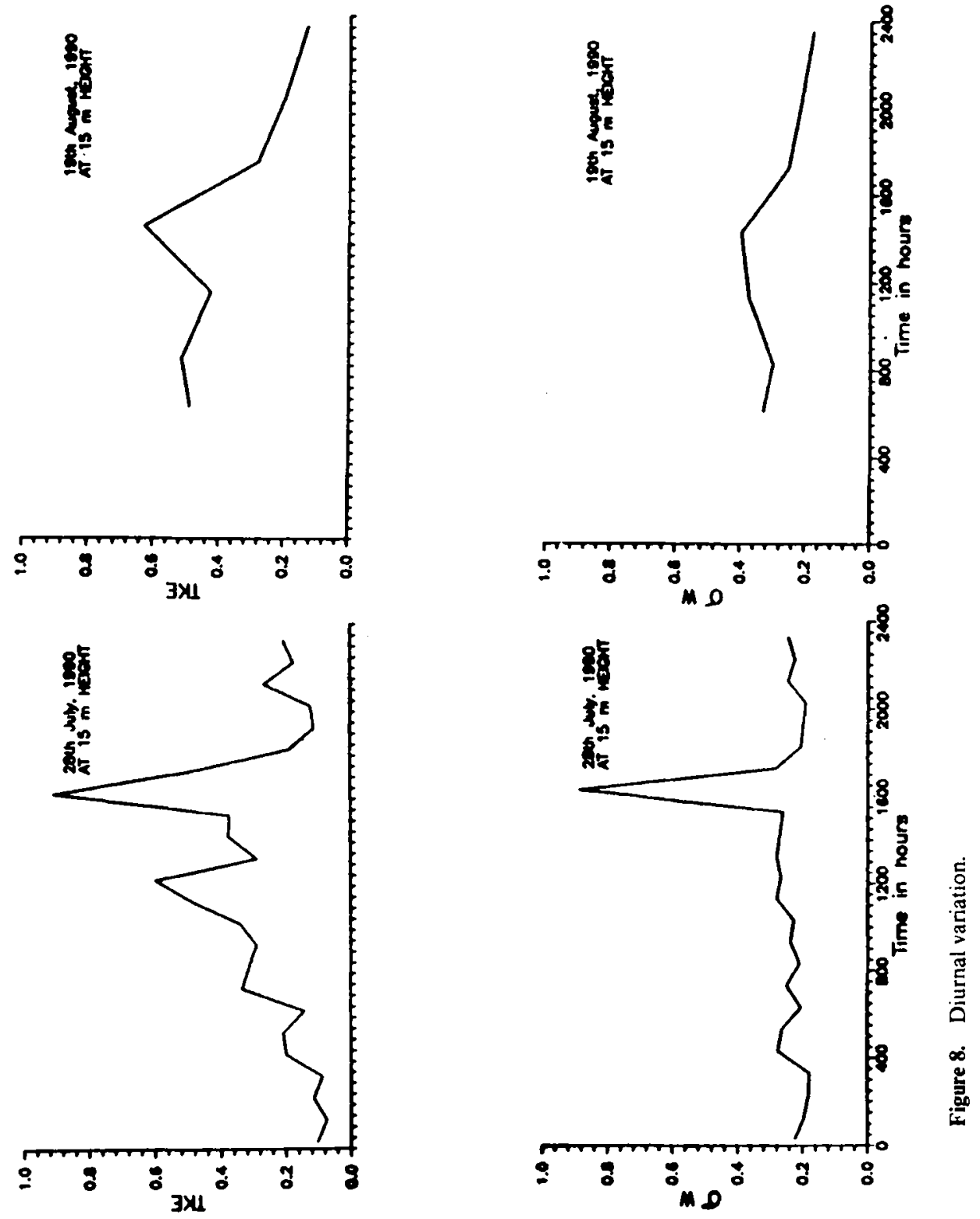

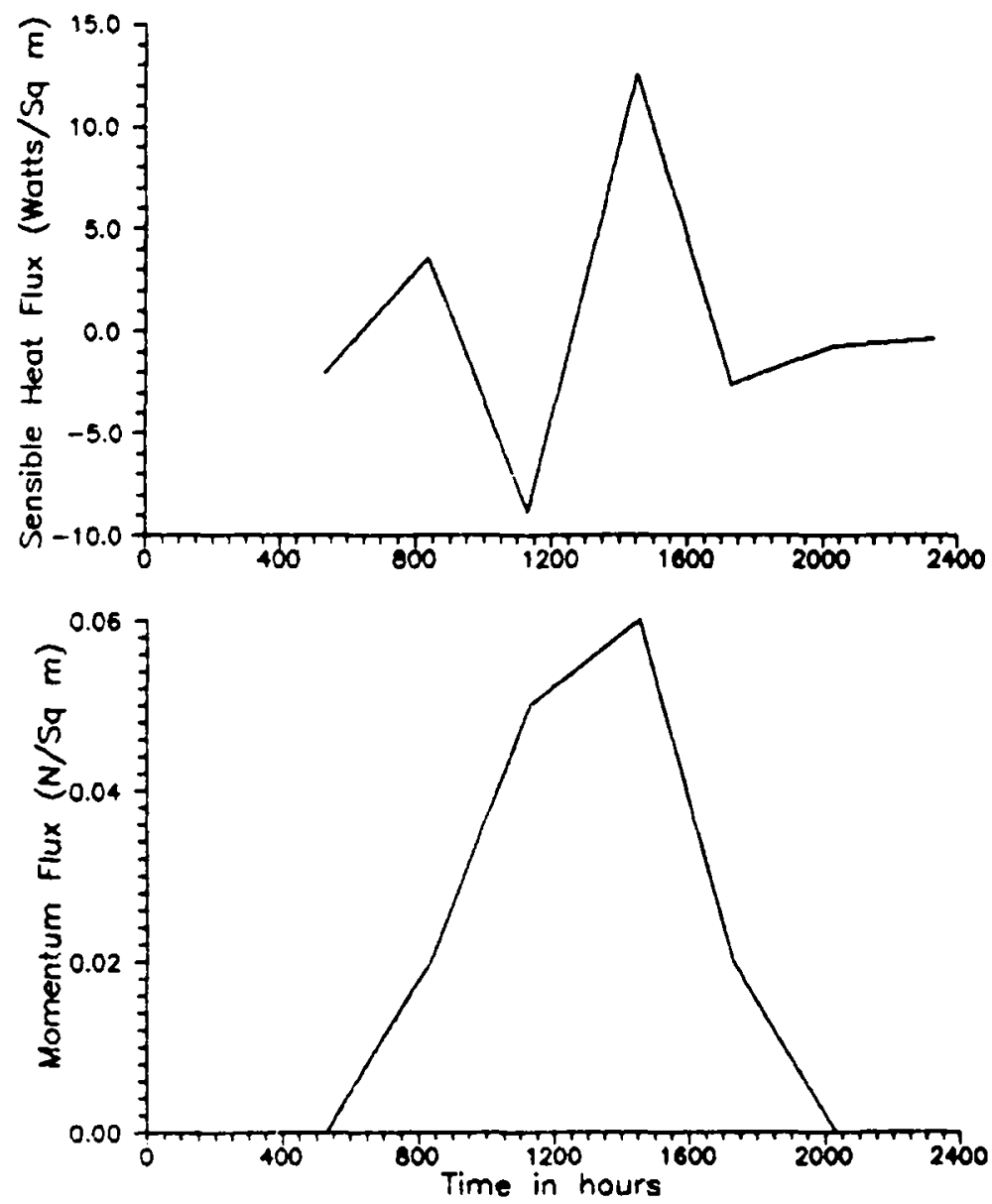

Figure 9. Diurnal variation of fluxes on 6th July, 1990 at $15 \mathrm{~m}$ height.

July 28th is considered as part of an active period: one can see the near-neutral conditions prevailing during both day and night. July 6th is neither dry nor active and hence is taken to represent moderate monsoon activity during which the diurnal variation shows a sort of trend tending to attain neutrality from unstable conditions. However the case of 19 th August, typical of a dry spell, clearly shows a high degree of instability at least in the 1-4 m layer, although it tends to attain neutrality. The free convective case at $2400 \mathrm{hrs}$ is inconsistent and hence inexplicable. The upper layer, however, shows neutral stability. Examination of the three cases at $15 \mathrm{~m}$ reveals very little diurnal variation. Whenever the monsoon is active diurnal variation diminishes, and whenever there is a break or a dry spell it becomes prominent, since in the latter unstable conditions prevail during day-time due to clear skies and stable conditions during night due to clear skies and calm conditions. However, during the active phase, the sky is over-cast and moist winds are present, both of which tend to stabilize the atmosphere from extremes i.e., from instability to less instability and from stable to less stable conditions. This is one of the important points to be borne in mind, that the 
activity of the monsoon has a bearing on the surface layer activities at least on stability. The fact that $1 / L$ is influenced by the activity of the monsoon suggests the general conclusion that all the activities in the surface layer, particularly energy exchange processes, do get influenced by monsoon activity.

On 19th August at the $15 \mathrm{~m}$ level, the conditions obtained from the Gill propeller do coincide with what was observed in the $4-30 \mathrm{~m}$ layer centring around $15 \mathrm{~m}$.

\section{$7.2 T K E$ and $\sigma_{w}$}

The diurnal variation of these two parameters at the $15 \mathrm{~m}$ level, which indicates the turbulence intensity, is shown in figures 7 and 8 respectively for the days mentioned already.

Both parameters exhibit striking variations. In general, the tendency is that relatively high values are noticed during night-time. Whether the monsoon is active or not, the parameters do not show any significant variation. This may be due to the fact that windy conditions induce turbulence during the active phase, and convective conditions during the inactive phase; therefore, there is every possibility of turbulence intensity
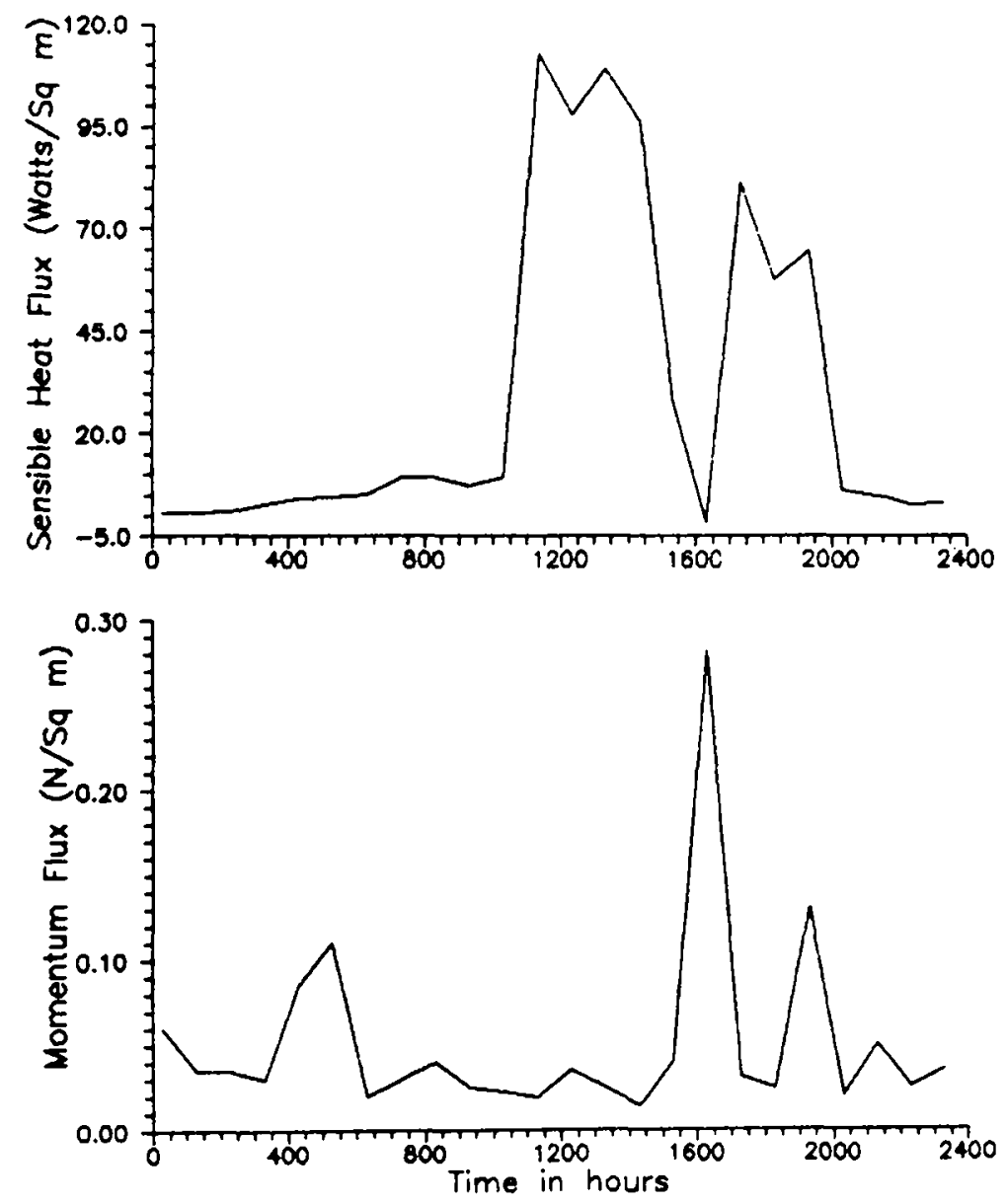

Figure 10. Diurnal variation of fluxes on $28 \mathrm{th}$ July, 1990 at $15 \mathrm{~m}$ height. 

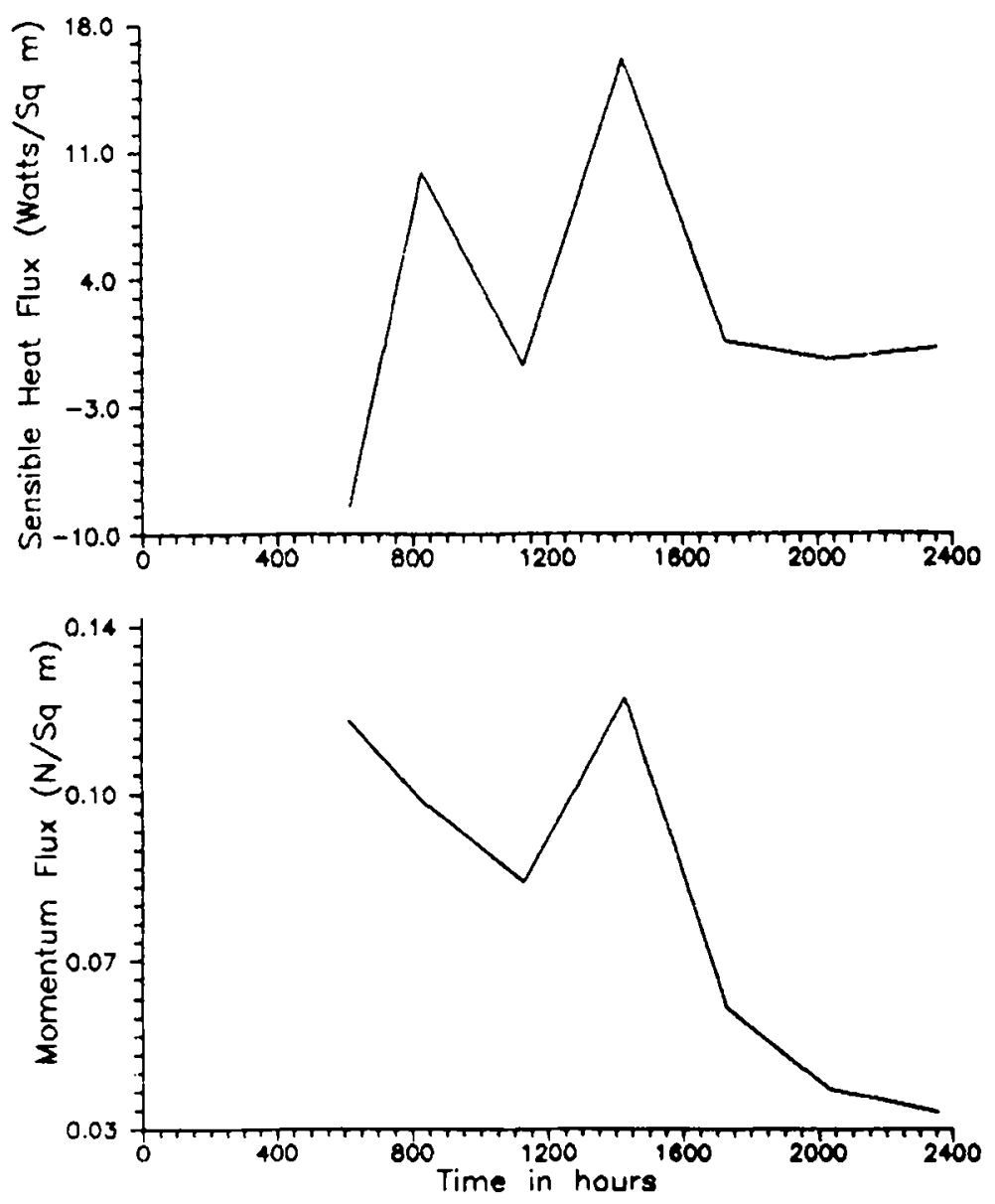

Figure 11. Diurnal variation of fluxes on 19 th August, 1990 at $15 \mathrm{~m}$ height.

and TKE varying little with the various phases of the monsoon. As mentioned already the diurnal variation is very striking, which can be attributed to individual hourly activities. One important point that comes out of this study is the quasi-randomness of turbulence not only within these micro limits of 10 minutes duration, but even on an hourly basis. In the present study there is a clear revelation that irrespective of day or night, hour-to-hour variations are quite significant although one can visualize a general trend showing relatively greater turbulence during day-time.

\subsection{MF and $S H F$ at $15 m$ height}

Figures 9 to 11 depict the diurnal variation on 6th July, 28th July and 19th August respectively.

On 6th July, MF is highest and shows a typical diurnal variation with the peak in the afternoon hours and lowest values during night-time. SHF on the other hand shows very little variation. 


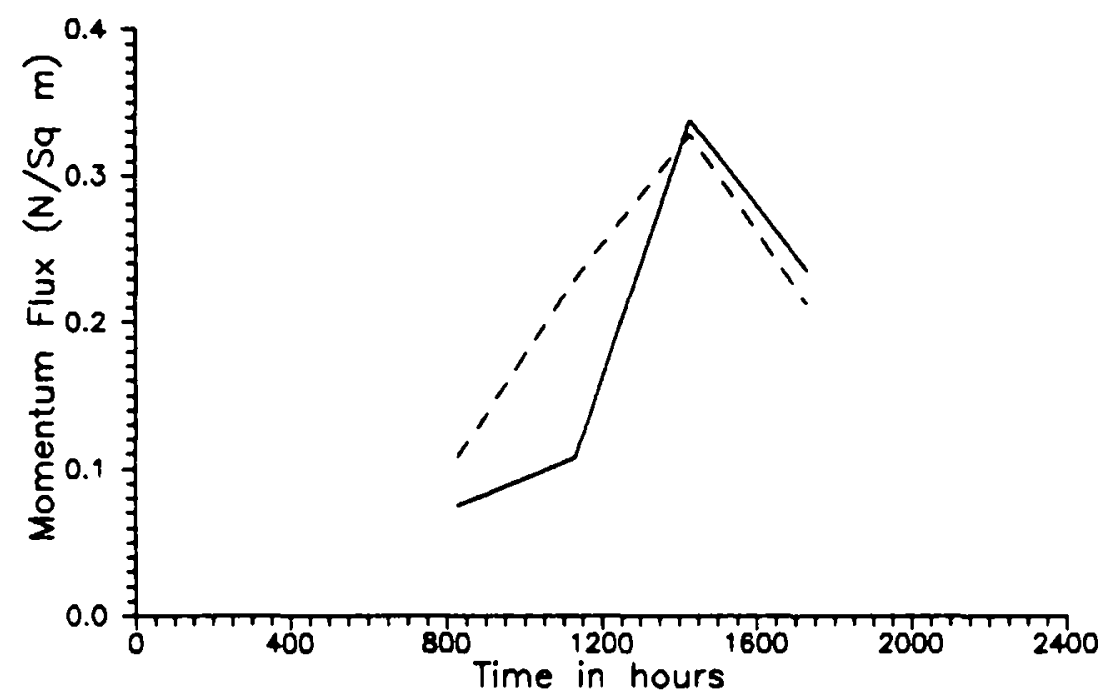

Figure 12. Diurnal variation of momentum flux on 6 th July, 1990;1-4 m layer (solid line), 4-30 $\mathrm{m}$ layer (dashed line).

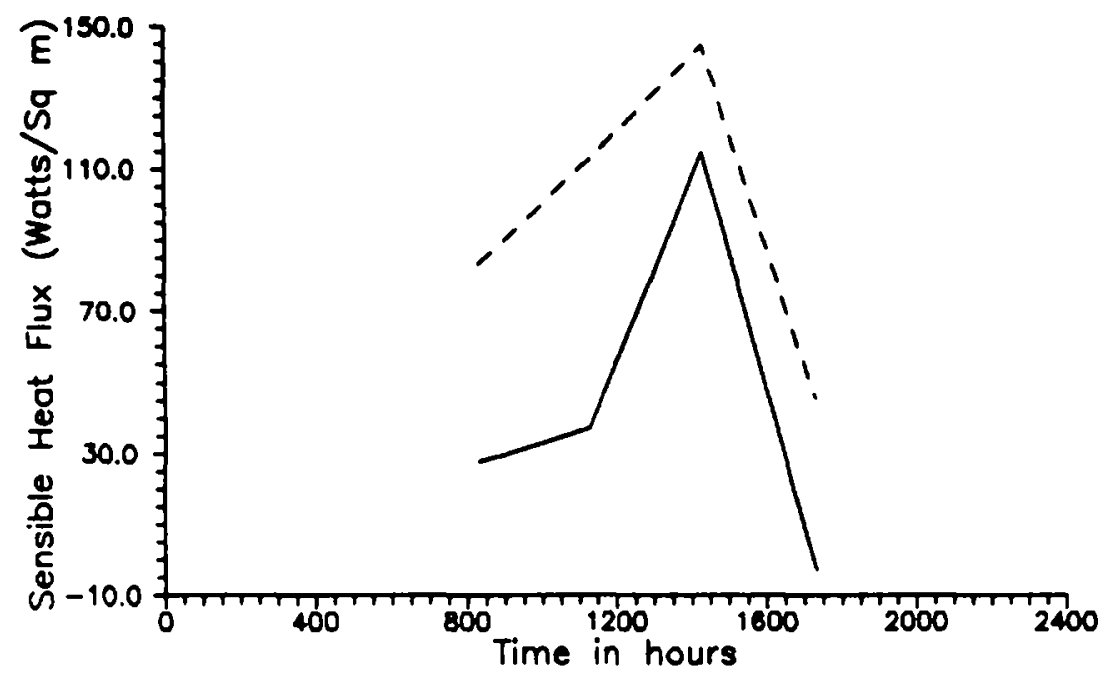

Figure 13. Diurnal variation of sensible heat flux on 6 th July, 1990; $1-4 \mathrm{~m}$ layer (solid line), 4-30 $\mathrm{m}$ layer (dashed line).

On 28th July, MF shows a distinct variation with several peaks. From 1600 to $2400 \mathrm{hrs}$, the variation is marked in MF. In SHF also, one finds variation from around 1100 to $2000 \mathrm{hrs}$, while it is invariant during the rest of the time. This is one day when hourly observations are available.

On 19th August, SHF is low and positive. MF decreases generally from early morning hours to midnight, except for a sudden increase at $1300 \mathrm{hrs}$. 


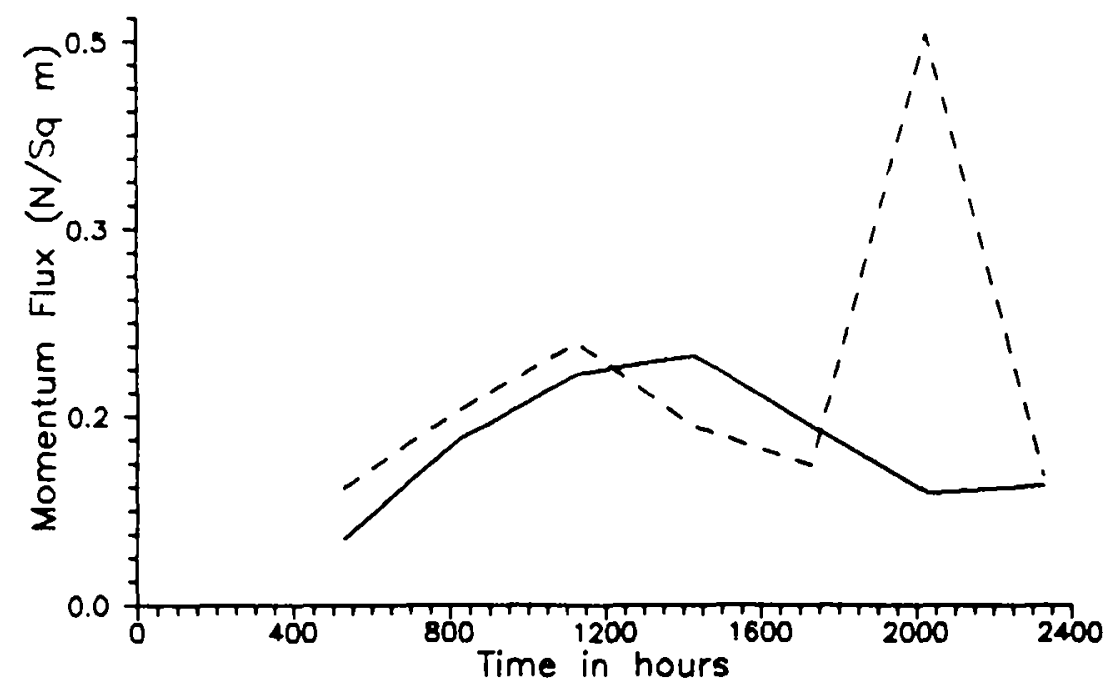

Figure 14. Diurnal variation of momentum flux on 28th July, 1990;1-4 m layer (solid line), 4-30 $\mathrm{m}$ layer (dashed line).

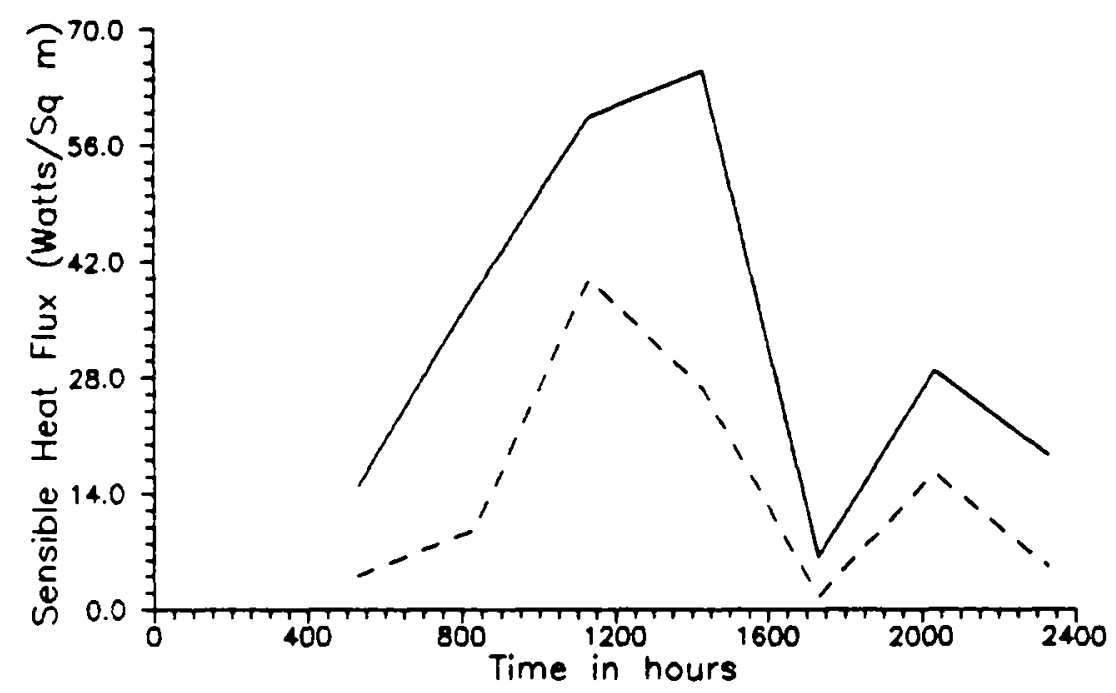

Figure 15. Diurnal variation of sensible heat flux on 28 th July, $1990 ; 1-4 \mathrm{~m}$ layer (solid line), 4-30 $\mathrm{m}$ layer (dashed line).

\subsection{MF and $S H F$ in $1-4 m$ and $4-30 m$ layers}

Figures 12 and 13 show the diurnal variation on 6 th July. MF variation is pronounced in both the layers with the peak being observed at $1300 \mathrm{hrs}$. SHF also exhibits similar variation. Upward fluxes are recorded almost all the time.

Figures 14 and 15 depict the diurnal variation on 28th July. MF clearly shows the diurnal variation on this day with higher values during day-time and low values during night except for the peak at $2000 \mathrm{hrs}$ in the upper layer. This peak is not very consistent, 


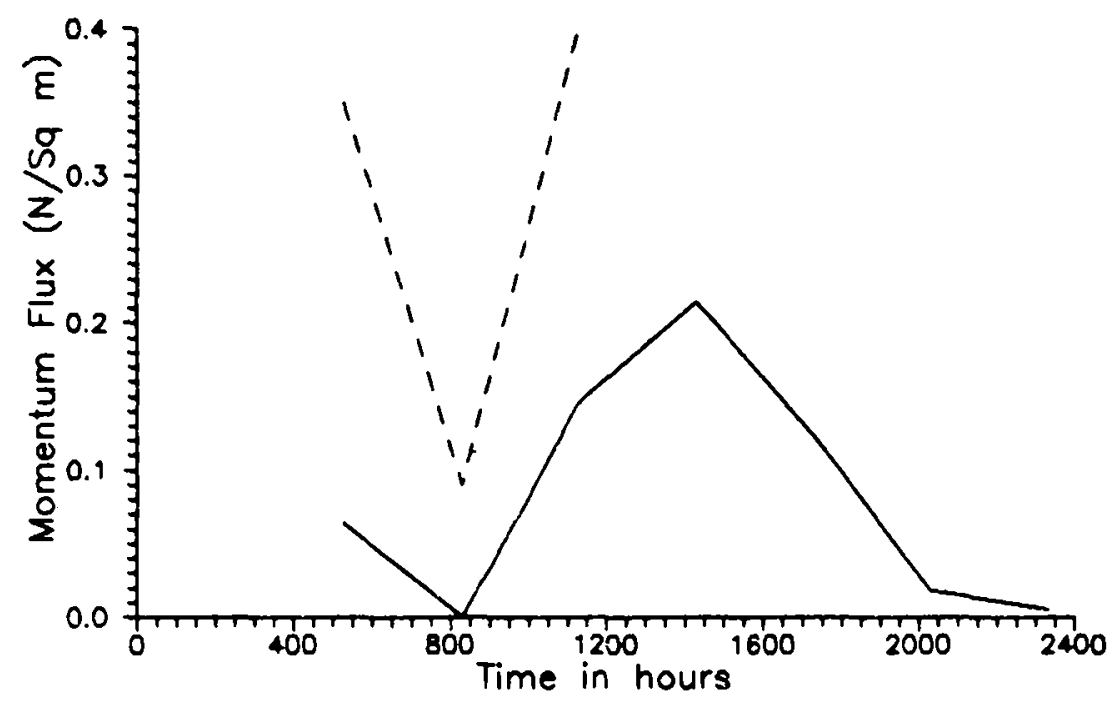

Figure 16. Diurnal variation of momentum flux on 18th August, 1990;1-4 m layer (solid line), 4-30 m layer (dashed line).

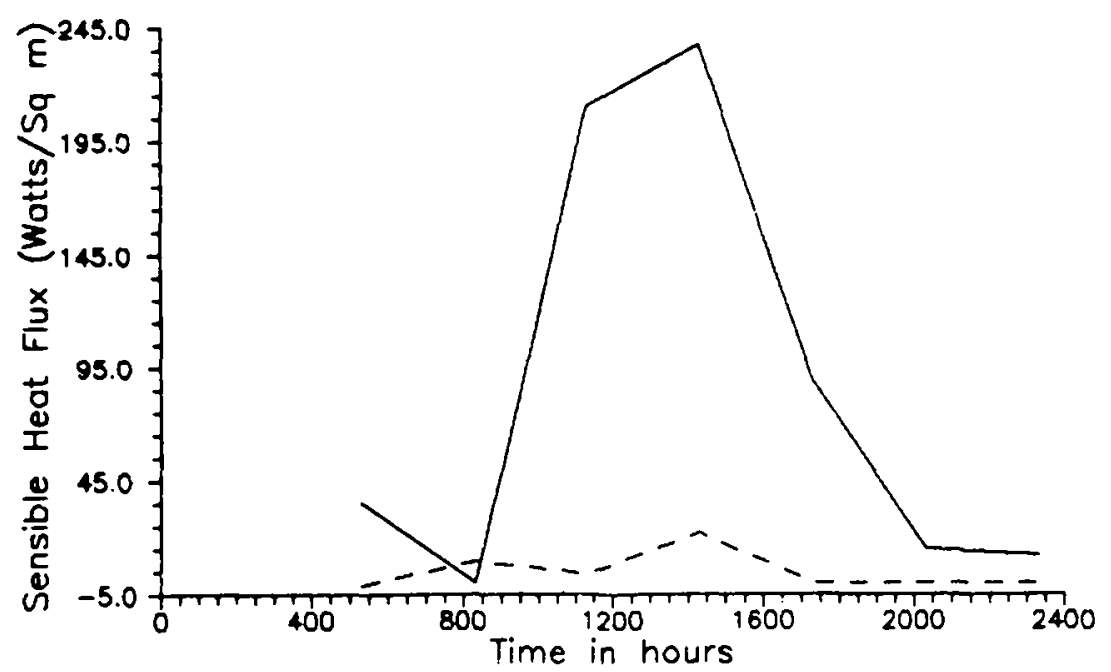

Figure 17. Diurnal variation of sensible heat fiux on 18th August, 1990; 1-4 m layer (solid line), 4-30 $\mathrm{m}$ layer (dashed line).

keeping the time of the observation in view. The maximum value is around $0.2 \mathrm{~N} / \mathrm{m}^{2}$ barring this unusual peak. SHF also shows diurnal variation but the values are below $60 \mathrm{~W} / \mathrm{m}^{2}$ in the upper layer and below $40 \mathrm{~W} / \mathrm{m}^{2}$ in the lower layer.

Figures 16 and 17 show the variation on 18 th August. One finds a strong diurnal variation in the 1-4 m layer. Not many observations are available in the upper layer. The SHF, however, shows strong diurnal variation in the lower layer and very little in the upper layer. Very high SHF is noticed on this day. 
It can be seen that whenever the monsoon is active the SHF shows little diurnal variation and also the values are low. If the monsoon is moderate or weak SHF is considerably more. Within the surface layer, differences in fluxes are noticed.

The overall study so far indicates that the stability parameter $(1 / L)$ shows its relation with the activity of the monsoon. The turbulence intensity parameters such as TKE and $\sigma_{w}$ do not show any significant variation with the activity of the monsoon.

The differences in the two layers within the surface layer are significant. Usually a $10 \%$ variation of parameters is observed. However, in the present case the variation is significant within the surface layer.

\section{Acknowledgements}

The financial support by DST, Govt. of India for carrying out this work is gratefully acknowledged.

\section{List of Symbols}

$$
\begin{array}{ll}
\rho & =\text { Density of air. } \\
g & =\text { Acceleration due to gravity. } \\
k & =\text { Von Karman constant. } \\
C_{p d} & =\text { Specific heat of dry air at constant pressure. } \\
\frac{q}{u^{\prime} w^{\prime}} & =\text { Specific humidity. } \\
\frac{v^{\prime} w^{\prime}}{w^{\prime} \theta^{\prime}} & =\text { Covariance between } u^{\prime} \text { and } w^{\prime} \\
U_{*} & =\text { Covariance between } v^{\prime} \text { and } w^{\prime} \\
\theta_{*} & =\text { Friction velocity } \\
L & =\text { Monin-Obukhov temperature. } \\
T & =\text { Atmospheric temperature. } \\
z & =\text { Height above the surface. }
\end{array}
$$

\section{References}

Blackman R B and Tukey J W 1958 The measurement of power spectrum, (New York: Dover Publications) 190 pp

Businger J A, Wyngaard J C, Izumi Y and Bradly E F 1971 Flux-profile relationships in the atmospheric surface layer; J. Atmos. Sci. $28901-917$

Champagne F H, Frieche C A and Largue J C 1977 Flux measurements, flux estimation techniques and fine scale turbulence measurements in the unstable surface layer over land; J. Atmos. Sci. 30 568-581

Holt T and Sethuraman S 1987 A comparison of the significant features of the marine boundary layer over the east central Arabian Sea and north central Bay of Bengal during MONEX-1979; Mausam 38 $171-176$

Pruit W O, Morgan D L and Lourence F J 1973 Momentum and mass transfers in the surface boundary layer; Q.J.R. Meteorol. Soc. 99 370-376 
Stull R B 1988 An Introduction to Boundary Layer Meteorology (Dordrecht/Boston/London: Kluwer Publishers) pp 666

Viswanadham D V and Satyanarayana A N V 1992 Preliminary studies on the surface layer parameters for selected cases over Banaras as revealed by MONTBLEX-90, Proc. of work shop on preliminary scientific results of MONTBLEX, DST, 69-82 